\title{
"APRECIE COM MODERAÇÃO": A IDENTIDADE DA ORGANIZAÇÃO COMO DRAMA E ATOS DE PERFORMANCE
}

“DRINK IN MODERATION”: THE ORGANIZATION'S IDENTITY AS DRAMA AND ACT OF PERFORMANCE

"APRECIE CON MODERACIÓN": LA IDENTIDAD DE LA ORGANIZACIÓN COMO DRAMA Y ACTOS DE REPRESENTACIÓN

\section{RESUMO}

A questão do que constitui a identidade de uma organização motivou produtivas conversações em busca de teorias, desde os anos 1980. Neste estudo, conduzimos o diálogo entre essa literatura e os conceitos desenvolvidos no campo da Antropologia da Performance. Como elemento facilitador desse diálogo, nós apresentamos, a título de ilustração, o processo de construção identitária da Ambev, companhia do setor de bebidas, em um período de contestação das regras sobre o consumo de álcool. Nossa análise mostra a natureza relacional do conceito de identidade da organização, um processo de múltiplas e fluidas interações construído em situações dramáticas e por atos de performance. Às questões que capturam a essência desse conceito, já presentes na literatura, nós adicionamos outra - "O que ou quem estamos nos tornando como organização?"

PALAVRAS-CHAVE Drama, identidade corporativa, identidade organizacional, mosaico, performance.

\author{
Jacquelaine Florindo Borges jac.borges@uol.com.br \\ Professora da Faculdade de Gestão e Negócios, Universidade Federal de Uberlândia - Uberlândia - MG, Brasil
}

Cintia Rodrigues de Oliveira Medeiros cintia@fagen.ufu.br

Professora da Faculdade de Gestão e Negócios, Universidade Federal de Uberlândia - Uberlândia - MG, Brasil

Recebido em 21.02.2009. Aprovado em 05.01.2011

Avaliado pelo sistema double blind review

Editor Científico: Eduardo Davel

\begin{abstract}
The issue of what constitutes an organization's identity has motivated productive dialogues in search of theory since the 1980s. In this study, the dialogue is between this literature and the concepts developed in the field of Anthropology of Performance. To illustrate a facilitating element of this dialogue, we present AmBev's (a beverage company) identity construction process during a period when the rules of alcohol consumption were being challenged. Our analysis shows the relational nature of the organizational identity concept, a process with multiples and fluid interactions constructed in dramatic situations and by act of performance. Besides the issues that involve the essence of the concept - already present in the literature - we have added another one: 'what or who are we becoming as an organization?'

KEYWORDS Drama, corporate identity, organizational identity, mosaic, performance.

RESUMEN La cuestión de lo que constituye la identidad de una organización ha motivado productivas conversaciones en busca de teorías, desde los años 1980. En este estudio, conducimos el diálogo entre esa literatura y los conceptos desarrollados en el campo de la Antropología de la Representación. Como elemento facilitador de ese diálogo, nosotros presentamos, a modo de ilustración, el proceso de construcción de la identidad de la Ambev, compañía del sector de bebidas, en un periodo de contestación de las reglas sobre el consumo de alcohol. Nuestro análisis muestra la naturaleza relacional del concepto de identidad de la organización, un proceso de múltiples y fluidas interacciones construido en situaciones dramáticas y por actos de representación. A las cuestiones que capturan la esencia de ese concepto, ya presentes en la literatura, nosotros les adicionamos una otra - "¿Lo qué o quién nos estamos convirtiendo como organización?"
\end{abstract}

PALABRAS CLAVE Drama, identidad corporativa, identidad organizacional, mosaico, representación. 


\section{INTRODUÇÃo}

- Você! Quem é você? Disse a Lagarta.

- Acho que você deveria dizer-me, primeiro, quem é a senhora [Disse Alice].

- Por quêe? Pergunta a Lagarta.

\section{Alice no país das maravilhas, Lewis Carroll}

Em um contexto em que as redes sociais multiplicam-se e as formas de transmissão e troca instantânea de texto, imagem e som ampliam-se, as organizações passam a mobilizar sofisticados argumentos para responder às questões que dizem respeito à sua existência. A identidade da organização torna-se um aspecto central para a prática e a pesquisa em Administração. Os estudos sobre o tema deram origem a duas abordagens e dois conceitos: identidade organizacional (IO) e identidade corporativa (IC).

A IO emerge dos estudos organizacionais e considera que crenças e princípios básicos definidos e compartilhados pelos membros da organização permitem que esses respondam à questão: "Quem nós somos como organização?". A IC emerge das áreas de marketing, design, estratégia e comunicação; considera que símbolos e artefatos visuais utilizados nas ações estratégicas e na construção da imagem e reputação da organização permitem aos executivos responderem à questão: "Como comunicar aos outros quem nós somos como organização?". Além dessas duas abordagens, três perspectivas teóricas emergiram das pesquisas sobre identidade de organizações: funcionalista, interpretativa e pós-moderna.

Neste estudo teórico-empírico, não estamos propondo a integração dos elementos da IO e IC, a qual é defendida por Hatch e Schultz $(1997,2000,2004)$ e por Rindova e Schultz (BOUCHIKI e outros, 1998), tampouco nós definimos a priori uma filiação teórica de nossa pesquisa a uma das perspectivas sobre identidade da organização. Nosso objetivo é desenvolver outros olhares sobre a questão da identidade, buscando desvendar aspectos ainda não considerados pelas perguntas que atualmente orientam os estudos sobre a identidade da organização.

Para isso, examinamos os conceitos desenvolvidos em uma área de conhecimento cujas contribuições para os estudos sobre a identidade de organizações são, ainda, incipientes: a Antropologia da Performance. Alguns estudos organizacionais apontam para a necessidade de uma aproximação entre identidade e performance: Hardy, Palmer e Phillips (2000) examinam a relação entre atividades discursivas e performance como um poderoso caminho para a compreensão dos processos de organização e, particularmente, das fragilidades e das forças na vida organizacional. Outros dois estudos consideram que as organizações competem, cada vez mais, baseadas em sua habilidade para expressar "quem elas são" e "o que elas significam". Wood Jr. (2000) e Schultz, Hatch e Larsen (2000) mostram que a expressividade emocional e simbólica torna-se parte da experiência de fazer negócios, gerando o que esses autores chamam, respectivamente, de organizações de simbolismo intensivo e organizações expressivas.

Neste artigo, apresentamos conceitos e perspectivas teóricas sobre a identidade da organização, nas duas primeiras seções. Em seguida, buscamos outros olhares para essa questão nos estudos da Antropologia da Performance. A seguir, analisamos o processo de construção identitária de uma companhia do setor de bebidas - a Ambev, no período de janeiro de 2003 a julho de 2010, quando as regras para o consumo de bebida alcoólica são contestadas e revistas. Implicações e conclusão da pesquisa encerram o artigo.

\section{IDENTIDADE ORGANIZACIONAL OU CORPORATIVA? OPOSIÇÃO E CONVERGÊNCIA CONCEITUAL}

O tema identidade tem uma longa trajetória em diversos campos do conhecimento. Com base no vasto e diverso corpo de pesquisas sobre a identidade individual, estudiosos do campo da Administração vêm desenvolvendo o conceito científico de identidade da organização. Em um trabalho seminal, Albert e Whetten (1985) defenderam a importância desse conceito para a prática organizacional, ao afirmar que questões de identidade são propostas, frequentemente, por gestores quando esses não têm informações suficientes para orientar as suas decisões. Essas questões são: quem nós somos? Que tipo de negócio nós estamos desenvolvendo? O que nós queremos ser? Esses autores propuseram uma definição preliminar do que uma declaração de IO deve conter: os aspectos que são, de algum modo, vistos como a essência da organização (centralidade), os aspectos que distinguem a organização de outras com as quais ela possa ser comparada (distintividade) e os aspectos relacionados às qualidades e características que, intencionalmente, a organização ou os seus membros desejam manter e preservar ao longo do tempo (continuidade).

Albert e Whetten (1985) consideram que essas três propriedades constituem um conjunto suficiente de critérios para se definir a IO como um conceito científico e sugerem questões e hipóteses de pesquisa. Para eles, a identidade é um ato político-estratégico, portanto não existe uma única 
e melhor declaração de identidade, mas, sim, múltiplas declarações igualmente válidas, uma vez que elaboradas por diferentes propósitos para atender diferentes audiências. Além disso, vários fatores podem tornar impossível a elaboração de uma declaração simples de identidade ou, ainda, dar origem a declarações ambíguas e imprecisas, entre eles, a complexidade do ambiente, o ciclo de vida organizacional e o amplo conjunto de características organizacionais.

Albert e Whetten (1985) afirmam que a IO pode ser compreendida internamente pela questão "Quem nós somos?" e, externamente, pela questão "Que tipo de organização é essa?". Os autores avaliam que a identidade publicamente apresentada difere da identidade internamente percebida por ser típica e igualmente mais positiva e monolítica, visto que as organizações tendem e preferem ver a si mesmas como capazes de abrigar interesses e valores diversos. Ainda, que a grande discrepância entre o modo como uma organização vê a si mesma e o modo como os outros a veem pode reduzir a efetividade organizacional e ameaçar a existência da organização, devido às dificuldades dessa para obter recursos e suporte político.

A despeito das contribuições de Albert e Whetten (1985) nesse e em outros trabalhos (ALBERT, 1998; WHETTEN, 2006), estudos posteriores questionaram a ênfase do conceito de IO em aspectos internos da organização. Pesquisadores das áreas de marketing, design, comunicação e estratégia argumentam a favor do conceito IC, que contempla as relações da organização, seus membros e sua equipe de gestores com os diferentes públicos externos. Esse conceito tem como base o que a organização expressa e "formalmente diz ser" para diversas audiências. Identidade é, conceitualmente, uma função da liderança que formula respostas para questões dirigidas para uma audiência externa: "Como comunicar aos outros quem nós somos como organização?" e/ou "Que organização/negócio nós queremos ser?". A identidade pode desempenhar papel essencial na definição de uma agenda estratégica (STIMPERT, GUSTAFSON, SARASON, 1998).

O conceito de IC atende a necessidade dos gestores de desenvolver de maneira planejada uma autorrepresentação ou autodeclaração da organização para orientar decisões, comunicação e comportamentos. A identidade é interdependente da imagem e da reputação organizacionais, consideradas partes constituintes das interações entre organização e audiência externa, nas diferentes situações em que a organização expressa para essa audiência "o que a organização é" (BROWN e outros, 2006), em um processo de sedução que busca visibilidade e legitimação no mercado (CHRISTENSEN e CHENEY, 2000).
A integração dos conceitos IO e IC é proposta por Hatch e Schultz $(1997,2000,2004)$ e por Rindova e Schultz (BOUCHIKI e outros, 1998). Essas autoras entendem que criar um corpo integrado de conhecimento, pensamento e prática é um passo necessário para elaborar um conceito que contemple a multiplicidade de relações entre membros, gestores, organização e contexto. Afinal, o fluxo dessas relações colapsa as distinções interno-externo e revela a existência de complementaridade e interdependência entre cultura, identidade e imagem.

A integração dos conceitos de IO e IC pode ser alcançada por um modelo multinível da identidade da organização, conforme Rindova e Schultz (BOUCHIKI e outros, 1998). Em um nível mais profundo, esse é um conjunto de crenças; em um próximo nível, é um conjunto de símbolos que modelam e orientam aquelas crenças; no nível seguinte, mais visível, é constituída por artefatos físicos e comportamentos manifestados. Tal modelo contempla os modos de expressão da IO e da IC, que operam em níveis diferentes de consciência. Esse fator torna-se essencial para a comunicação com diversas audiências e para a efetividade organizacional.

\section{CRENÇAS, SIGNIFICADOS E FRAGMENTAÇÃO: CONSTRUINDO TEORIAS}

Durante os verões de 1994, 1995 e 1996, um grupo de pesquisadores reuniu-se com o propósito de investigar e construir uma teoria com base em conversações sobre o tema identidade em organizações (WHETTEN, GODFREY, 1998). Também no Brasil, pesquisadores têm se dedicado a entender e comprovar empiricamente suas hipóteses sobre esse tema (CARRIERI, PAES DE PAULA, DAVEL, 2008). Nós apresentamos, a seguir, as ideias centrais que fundamentam a ontologia, a epistemologia e a metodologia das perspectivas funcionalista, interpretativa e pós-moderna da identidade de organizações.

A perspectiva funcionalista concebe identidade como um conjunto de crenças institucionalizadas que modelam as ações dos membros da organização nos níveis individual e organizacional para responder à seguinte questão: "Quem nós somos, dado o status social que adquirimos?". Esses estudos adotam os seguintes pressupostos: a identidade existe objetivamente como um fato social, observável e manipulável; a identidade influencia as ações; essas ações podem ser geridas e controladas; e a identidade pode ser gerida e transformada para diferentes propósitos. Metaforicamente, a identidade é um objeto, com cor, forma, função e outras características que podem variar 
em grau de utilidade para as organizações, sendo mesmo um ativo, um recurso.

Pesquisas com essa perspectiva buscam identificar como a identidade afeta a cognição dos membros da organização, como isso influencia ações individuais e coletivas e, também, identificar, descrever, medir e, de um ponto de vista gerencial, tornar possível a gestão produtiva da identidade. Esses estudos investigam características objetivas da organização, como a relação entre demografia e crenças, os padrões de decisão e as declarações dos membros, especialmente, dos gestores. Preferencialmente, utilizam-se métodos de investigação que possam medir ou representar, de modo objetivo, as dimensões da identidade, como instrumentos utilizados em psicometria e técnicas de mapeamento cognitivo (DUTTON, DUKERICH, 1991; MACHADO-DA-SILVA, NOGUEIRA, 2001; PRATT, FOREMAN, 2000; RINDOVA, POLLOCK, HAYARD, 2006; Rindova, Bouchikhi, Rao em BOUCHIKI, 1998).

A perspectiva interpretativa concebe identidade duplamente como fluxo e processo de construção e compartilhamento coletivo de significados pelos membros da organização, em resposta à seguinte questão: "O que ou quem nós somos como organização?". Esses estudos adotam os seguintes pressupostos: a identidade é um conjunto de significados construídos e aceitos pelas pessoas; a identidade não existe objetivamente nem pode ser facilmente manipulável; a identidade é social e inevitavelmente construída e renegociada; as pessoas em grupos sociais têm necessidade de certa estabilidade dos significados; e os grupos sociais sempre irão buscar algum nível de convergência entre os significados e suas próprias identidades.

Com menos ênfase na questão da utilidade, duas metáforas explicam essa perspectiva da identidade: o teatro, um amplo conjunto de regras e atores que improvisam no palco, além de, constantemente, definirem os seus papéis e suas interações; holograma ou cérebro, o conhecimento e a construção da identidade estão distribuídos entre os membros, aspecto essencial para a cultura dos grupos e da organização. Pesquisas com essa perspectiva buscam descobrir/revelar significados e estruturas de significados negociados entre os membros da organização. Pesquisas, preferencialmente de natureza qualitativa, investigam símbolos e tudo aquilo que tem significado para os membros: linguagem, artefatos, maneirismos, visão de mundo e esquemas interpretativos utilizados para dar sentido àqueles símbolos (Fiol, Gioia em BOUCHIKI, 1998; GIOIA, SCHULTZ, CORLEY, 2000; GLYNN, 2000; HASLAM, POSTMES, ELLEMERS, 2003; RAVASI, SCHULTZ, 2006).

A perspectiva pós-moderna problematiza a própria noção de identidade, definida como reflexões transitórias e fragmentadas a respeito de "quem nós assumimos ser para nós mesmos?". Esses estudos adotam os seguintes pressupostos: indeterminação dos significados; identidade como coleção acidental de formas agrupadas ou reunidas em um momento do tempo; formas paradoxais da identidade devido à mistura de significados presentes de modo fragmentado na organização, competindo por dominância; e pluralidade e multiplicidade de identidades. Ainda que essa perspectiva recuse a adoção de uma única metáfora, a colagem é a metáfora utilizada por significar grande variedade de identidades possíveis, ideias momentâneas que orientam a construção de identidades fragmentadas e justaposição de elementos inesperados que dão um novo e surpreendente sentido para algo não antecipado. Pesquisas com essa perspectiva buscam dar voz a atores marginalizados pelo status quo e identificar, por meio de provocação e reflexividade, silêncios ou ausências nos discursos. Linguagem e discurso são dimensões-chave desses estudos, a desconstrução, o método privilegiado (CALDAS, WOOD JR., 1997; CZARNIAWSKA, 2000; BROWN, A. D, 2006; FONTENELLE, 2007; HATCH, SCHULTZ, GOLDENBIDDLE em BOUCHIKI, e outros, 1998; MACHADO, 2005; SCHULTZ, HATCH, LARSEN, 2000; YBEMA, 2010).

Existem também evidências de convergência nos estudos da identidade da organização. Além do trabalho colaborativo entre autores de perspectivas diferentes, há o relativo consenso de que a identidade é "uma noção relacional" (BOUCHIKI e outros, 1998, p. 41) e um "construto de natureza coletiva" que diz respeito a "uma entidade que busca definir a si mesma" (CORLEY e outros, 2006, p. 87). Outro ponto de relativo consenso é a natureza dual da formação da identidade da organização, que envolve a interação entre pessoas e aspectos internos e externos (SCOTT, LANE, 2000), com o reconhecimento de que a identidade é uma questão político-estratégica, muito embora cada perspectiva tenha a sua própria concepção da relação entre poder e identidade.

\section{IDENTIDADE, DRAMA E PERFORMANCE: EM BUSCA DE OUTROS OLHARES}

Nesta seção, nós examinamos os conceitos de drama e performance oriundos de um campo de pesquisa cujas contribuições para a identidade da organização são, ainda, incipientes, a Antropologia da Performance. Centramos a nossa análise nos estudos de dois expoentes desse campo de pesquisa, Turner (1985) e Schechner (2006, 2003). Antes, porém, destacamos alguns conceitos da obra de Erving Goffman, autor que também desenvolveu o concei- 
to de performance e é referência para Schechner e Turner (cf. TURNER, 1985, p. 181).

Performance é "toda atividade de um determinado participante, em dada ocasião, que sirva para influenciar, de algum modo, qualquer um dos outros participantes", define Goffman (1990, p. 26). Ele emprega a perspectiva da apresentação teatral e princípios de caráter dramatúrgico para desenvolver um quadro de referência das interações sociais, especialmente aquelas que ocorrem face a face. Nessas interações, um indivíduo irá mobilizar símbolos, conduta e aparência, enquanto os outros indivíduos ou plateia, com base em suas experiências anteriores com indivíduos parecidos, farão uso de estereótipos para saber quem aquele indivíduo é e o que se pode dele esperar. Goffman (1990) afirma que: (1) muitos fatos decisivos para a interação estão além do tempo e do lugar em que ela ocorre, e (2) a influência que o indivíduo tem sobre a definição da situação em que ele se apresenta (incluindo o controle da conduta dos outros indivíduos) é decisiva para o atingimento do seu objetivo

A performance ou expressão de um papel tem caráter promissório. Implicitamente, o indivíduo solicita à plateia que leve a sério a impressão que ele sustenta perante aquela. Nos estudos goffmanianos, as performances do self na vida cotidiana constituem as identidades, pois a produção do self é um empreendimento colaborativo relacionado à execução cotidiana de apresentações de si mesmo.

Esse conceito goffmaniano reflete a perspectiva interacionista simbólica de self. Nessa perspectiva, o self é designado pelo Eu e Mim (material, espiritual e social). O Eu é a raiz da identidade pessoal do "sujeito" e o Mim, a autoconcepção. O Mim social é o reconhecimento que obtemos dos outros e a imagem que eles fazem de nós. Existirão "tantos selves sociais quantos forem os círculos de relacionamento de que participa uma pessoa", pois o self social resulta de processos de "comunicação significante com os outros" (NUNES, 2005, p. 49). E, também, dos personagens representados, das apresentações triunfantes, das estratégias dramatúrgicas, da ansiedade e do medo do descrédito, assim como da capacidade para aprender, treinar para o papel, ter fantasias e ser cuidadoso com os assuntos que importam aos outros indivíduos (GOFFMAN, 1990).

\section{Drama social e performance}

Ao conceito de performance ou noção goffmaniana da apresentação do "eu" na vida cotidiana, Turner (1985) adicionou a ideia de que performances dizem respeito a experiências e, frequentemente, assumem a forma de rituais ou de dramas sociais. Influenciado pelos estudos pós-modernos da época, Turner (1985, p. 179) desenvolveu um método de análise que chamou de "análise de drama social".

A palavra drama é utilizada nos estudos desse autor como metáfora e como paradigma. Ao empregar a terminologia teatral, para analisar situações de contestação (guerras, revoluções, mudanças de status e mudanças sociais), Turner (1985) afirma que, diferentemente de Schechner e Goffman, as interações se tornam dramatúrgicas com o início da ruptura nas relações sociais ou quando crises emergem no fluxo dessas interações. Dramas sociais são, igualmente, "unidades harmônicas e desarmônicas do processo social" (TURNER, 1975), surgem em situações de conflito de paradigmas. Nessas situações, os atores dão forma às suas ideias (aprendidas ou adquiridas com a experiência) e se engajam em ações sociais que, em determinadas circunstâncias, produzem novos arranjos sociais.

Esse autor analisa o papel transformador e inovador de ações simbólicas representadas nos momentos da vida social em que o conflito de paradigmas dá origem aos dramas sociais. Esses se desenrolam em quatro fases principais: (1) início dos eventos de ruptura do fluxo das relações sociais regularmente governadas por normas ou contratos, período marcado por rituais ou atos ritualizados; (2) período de crise marcado por um ínterim espaço-temporal de transição de status, posição, normas; ou, ainda, situações em que verdades e tabus que caracterizavam a vida pública são revistos e contrapostos; (3) ações de compensação e reparação, período de atuação política e jurídica intensa marcado por rituais de performance pública para legitimar os modos de resolução da crise; e (4) reintegração dos grupos sociais ou o reconhecimento de uma cisão irreconciliável entre as partes em conflito.

Se a vida diária é um tipo de teatro, avalia Turner (1985, p. 181), o drama social é um metateatro, ou seja, "uma linguagem dramatúrgica a respeito da linguagem das relações e trocas diárias de papéis (role-playing) e da manutenção de status". E, "se a performance pode ser vista como um objeto legítimo de estudo para a Antropologia Pós-Moderna", Turner (1985, p. 187) afirma ser apropriado não apenas examinar os tipos de performance, indo além da etnografia, mas desenvolver o conceito de Homo performans - "o homem como um animal que se autoperforma". Performances de papéis são processos reflexivos de apresentação do "eu"em que o ator pode vir a conhecer melhor a si mesmo e, com base em sua atuação e apresentação, revelar-se para si mesmo; também um grupo de seres humanos pode vir a conhecer melhor a si mesmo a partir da observação e/ou participação na performance gerada e apresentada por outro grupo de seres humanos. 
A Antropologia da Performance recusa o individualismo e o coletivismo como epistemologias por entender que paixões, vontades, comportamentos e razão estão na origem de resíduos, rasuras, interrupções e tropeços (TURNER, 1985) que levarão a uma espécie de "contrateatro" da vida cotidiana (DAWSEY, 2005). Afinal, drama social é uma "unidade empírica do processo social do qual está sendo derivado"; e performances, especialmente as dramáticas, "são manifestações por excelência de processos sociais humanos" (TURNER, 1985, p. 190 e 199).

\section{Performance e identidade}

Nos negócios, "to perform" é "fazer alguma coisa além do padrão" (SCHECHNER, 2006, p. 28), é ter êxito, ser bem-sucedido, superar, ultrapassar. As performances estão em vários lugares e fazem parte da vida das pessoas, todavia explicar o significado de performatividade e performativo não é algo simples, pois as origens conceituais dessas duas palavras relacionam-se a estudos de diversas áreas de conhecimento (SCHECHNER, 2006).

Essas palavras são utilizadas, muitas vezes, de modo pouco preciso. Nem toda ação, comportamento e evento são, mas eles podem ser estudados "como" performance. O que "é" performance refere-se a eventos mais definidos e marcados por contexto, convenções, usos e tradições. A definição do que "é" e do que "não é" performance parte da própria sociedade. Todavia, no mundo contemporâneo e midiatizado, as oportunidades ampliadas de um indivíduo transmitir e receber informações colapsam as fronteiras entre "como" performance e "é" performance (festas, entrevista de trabalho, papéis de gênero, papéis profissionais como médico e professor, e-mails e blogs).

Turner e Schechner distinguem performance social e performance estética ou cultural (própria das artes e que ocorre com um grau maior de distanciamento), mas entendem que a estética também está presente na primeira, tornando a performance um conceito inclusivo. Eles distinguem comportamento de experiência; o primeiro está mais sujeito à padronização e é descrito pelos outros e/ ou por uma audiência; o segundo é mais pessoal, refere-se a um ativo, ao humano que não apenas engaja, mas também modela essa ação porque, além de fazer e sentir, é capaz de refletir sobre a ação e o sentimento (BRUNER, 1986; SCHECHNER, 2006).

O conceito de performance traz em si, portanto, um problema epistemológico: nós não podemos conhecer diretamente as experiências dos outros, o que nos faz a todo instante buscar pistas e fazer inferências. Mesmo quando compartilhadas, as experiências estão submetidas a sensores e repressores pessoais e coletivos, à capacidade de cada um de articular os aspectos de sua experiência, à memória e ao grau de consciência desses aspectos. A apreensão das experiências dos outros só é possível pela interpretação de suas expressões, que se manifestam de diferentes maneiras: escrita, corporal, oral, desenhos, mímicas, diários, estórias, narrativas, carnaval, murais, concertos (BRUNER, 1986; SCHECHNER, 2003; TURNER, 1985).

A complexidade existencial das expressões não impossibilita que elas sejam isoladas e acessíveis, pois, em geral, elas têm um começo e um fim, ocorrem por um tempo limitado envolvendo performers e audiência (SCHECHNER, 2006; BRUNER, 1986). Isso torna possível que as expressões, entendidas como articulações, formulações e apresentações das pessoas sobre suas próprias experiências, constituam as unidades básicas que nos permitem analisar uma cultura ou um processo social. Além das expressões, para representar, um indivíduo precisa aprender, treinar, criar, desenvolver e inventar os recursos performativos ou todo material subjetivo e objetivo utilizado no processo, incluindo pessoas, espaço, dinheiro, coisas, objetivos, sentimentos, fantasias, interesses (SCHECHNER, 2006). Ainda assim, dispor de recursos não é garantia para o sucesso da performance; ela falha se não satisfaz o seu público e os críticos ou se não realiza aquilo que era intencionado.

\section{Desenvolvendo outros olhares sobre a identidade da organização}

Nesta seção, conduzimos um diálogo entre os conceitos e as perspectivas teóricas da identidade de organizações com os conceitos "drama social" e "atos de performance" do campo da Antropologia da Performance. Nós propomos um caso ilustrativo como fator facilitador desse diálogo: o processo de construção identitária da Companhia de Bebidas das Américas (Ambev), em um período crítico de sua existência. Essa companhia foi constituída em 1999, devido à fusão das duas maiores companhias do ramo de cervejas do Brasil (Brahma e Antarctica). Em 2004, em uma nova negociação, a Ambev foi adquirida por uma empresa belga (Interbrew), dando origem à companhia InBev. Posteriormente, com a incorporação de uma empresa canadense, passou a se intitular a Cervejaria das Américas. Em 2008, a empresa belgo-brasileira InBev adquiriu a companhia norte-americana Anheuser-Busch; essa operação gerou a maior cervejaria do mundo e a terceira maior empresa de bens de consumo do mundo em valor de mercado. Esses fatos deram à Ambev o status de empresa-celebridade (RINDOVA, POLLOCK, HAYWARD, 2006), empresa bem-sucedida e empresa internacional.

A despeito desse cenário favorável, no período de 
janeiro de 2003 a julho de 2010, a Ambev passa a estar no centro de um drama social, conforme definição de Turner $(1985,1975)$. Não bastassem os desafios do crescimento promovido por diversas aquisições, outros fatores contribuíram para que um novo e dramático cenário se configurasse: implantação da nova Política Nacional para o Consumo de Álcool (chamada Lei Seca); aspectos polêmicos da "cultura Ambev" noticiados pela mídia e redes sociais (jornais, revistas, internet); decisões judiciais desfavoráveis à companhia no âmbito da publicidade e das relações trabalhistas; além da entrada de novos concorrentes em um mercado conhecido pelas estratégias agressivas dos competidores.

Nesse período, diversos públicos implicados nessas transformações cogitam outras identidades para a Ambev e essa se insere no imaginário social como empresa cujos funcionários adoecem, empresa que viola as normas sociais, empresa que infringe a lei, empresa que deixa de ser brasileira, empresa que instrumentaliza o corpo da mulher, empresa que usa táticas de "guerra" contra os concorrentes.

No Brasil, o cerco social à indústria de bebidas alcoólicas amplia-se a partir de 2003. Especialistas em medicina e psiquiatria de conceituadas universidades do país, especialistas em serviço social e psicologia, legisladores, promotores, pais, mídia e ativistas anticorporação iniciam uma série de denúncias sobre o mal causado pelo consumo do álcool. Uma espécie de "aliança cidadã" (JORNAL FOLHA DE S. PAULO, 2003) se estabelece contra os problemas sociais e de saúde pública causados pelo consumo do álcool: mortes no trânsito, vandalismo e agressão, violência doméstica, aumento do consumo de álcool por jovens e mulheres, redução da idade com que jovens começam a consumir bebida alcoólica, incidência de câncer de esôfago e de fígado, epilepsia, doenças do coração, envelhecimento precoce, problemas em órgãos como rins, estômago, pâncreas, próstata, sistema reprodutivo, cérebro e memória. Maior rigor e "tolerância zero" ao motorista alcoolizado ilustram a existência de conflitos de interesses entre os objetivos de crescimento da Ambev e os objetivos sociais de redução do consumo de bebida alcoólica. Os valores sociais em defesa da saúde e da vida estão em conflito com o produto vendido pela companhia, que passa a ser visto como a antítese desses valores.

A fase de estabelecimento e desenvolvimento da crise caracteriza-se pela deterioração da identidade da companhia, no sentido goffmaniano: empresa que busca o lucro acima das pessoas, empresa que faz mal para a saúde (dos funcionários e dos consumidores). A sociedade questionava os males individuais, familiares e sociais do consumo de álcool, como demonstram as manchetes "Até a última gota", "25\% de motoristas mortos em 2005 eram jovens" e "No fundo do copo" (VAI UMA CERVEJINHA..., 2007). A Ambev se apresentava como aquela que tem como missão "Disponibilizar para o mercado as melhores marcas, produtos e serviços que possibilitem a criação de vínculos fortes e duradouros com os nossos consumidores e clientes". O texto ainda explicava: "A nossa missão é a razão fundamental de estarmos no negócio [...] Ela independe do tempo".

Nessa época, a empresa deixava claro o que esperava para o futuro: "Seremos os melhores do mundo na compreensão dos consumidores [...]", "Construiremos a liderança das nossas marcas com execução impecável". Também estava evidenciada a ênfase no crescimento lucrativo e nos interesses dos acionistas: "Montaremos uma equipe de craques que tenham foco, disciplina e imaginação para aumentar continuamente o valor da companhia" (AmBev, 2006). No texto postado em seu site corporativo, a Ambev indicava que, além dos acionistas, os consumidores e funcionários eram os públicos que mais interessam para os negócios.

Todavia, nessa fase, o que está em questão são exatamente as implicações da cultura, das práticas e das estratégias da Ambev para a saúde de consumidores e funcionários. Em 26 de abril de 2006, uma reportagem com o título "Cultura envelhecida", publicada na Revista Época (NEVES, CANÇADO, 2006), afirma que a Ambev é uma empresa que dá resultados elevados para os acionistas, "Mas o modelo da empresa, baseado na ambição, já não atrai tantos talentos como antigamente". A reportagem traz fotos e depoimentos de ex-funcionários da Ambev que falam de humilhações, adoecimento, excesso de carga de trabalho e pressão implacável por atingimento de metas.

Nesse período, notícias em jornais relatam situações de assédio moral e de multas por publicidade que infringe as leis ou normas para o setor protagonizadas pela companhia. Além disso, a mídia questiona o fato de que as indústrias de bebidas, armas e tabaco elegeram 65 deputados para a Câmara dos Deputados (de oposição e do governo) em um momento em que seus interesses estão sendo contestados. Nessa fase, Ambev e Souza Cruz não foram aceitas para fazer parte do Índice de Sustentabilidade Empresarial (ISE) da Bolsa de Valores de São Paulo (BOVESPA).

Em 20 de junho de 2008, entra em vigor a Lei 11.705, que torna crime beber e dirigir. Pesquisas feitas nessa semana indicavam a aprovação de $90 \%$ da população para essa lei. Além de multas, o motorista alcoolizado pode perder a carteira de motorista e ser preso. Na fase da compensação, a Ambev assume-se como parte da solução dos problemas advindos com o consumo do álcool - empresa que é parte da solução; ela não se identifica em nenhum 
momento no material pesquisado como parte do problema. Talvez os gestores tenham percebido que a audiência representada por pais, legisladores, judiciário, órgãos reguladores e especialistas não recuaria em seu propósito e julgamento. A empresa teria mais a ganhar em imagem e reputação se mudasse sua posição: em vez de negar o problema, assumir o papel de "alguém" que se preocupa com os direitos e deveres dos cidadãos. Em seu site corporativo, a Ambev apresenta-se como empresa cidadã que defende o consumo responsável. Essa apresentação é sustentada por ações e práticas que expressam essa identidade: seção de massagem para os funcionários, doação de bafômetros para órgãos públicos, ênfase na educação para o consumo em suas campanhas publicitárias "Beba com moderação" ou "Se beber, não dirija".

O que se destaca nessa fase é como as ações de compensação da companhia tornam-se ambíguas e contraditórias. A companhia apresenta-se como aquela que está empenhada em reduzir a "dependência", mas é nessa fase que a empresa firma parceria para aumentar o consumo de cerveja durante a semana, especialmente na quarta-feira, dia de jogos de futebol. Na fase de solução ou cisão do drama social, identificamos a conciliação de interesses entre a sociedade e a companhia. De modo geral, a primeira deixou de insistir na dependência alcoólica advinda com o consumo e passou a se concentrar na aplicação da legislação e na fiscalização, governo e especialistas passaram a comemorar os resultados positivos advindos com a Lei 11.705; isso atendia aos interesses da Ambev, que surge como empresa educadora, para a qual o álcool só se torna um problema se houver abusos ou consumo indevido; se consumido em doses adequadas, ele faz bem para a saúde. Essa identidade é performada pela companhia em textos que combinam emoção, cuidado, empatia e parceria, como nesta frase em seu website: "Trabalhamos para que dois amores da sua vida nunca andem juntos: sua cerveja e seu carro" (AMBEV, 2010).

Nessa fase, empresas cujos produtos são considerados nocivos à saúde, como bebidas, tabaco, entre outros, intensificam ações consideradas de responsabilidade social. O texto da missão da Ambev, em 2010, mantém a essência do que ela apresentava em 2006 - "Criar vínculos fortes e duradouros com os consumidores e clientes, fornecendo-lhes as melhores marcas, produtos e serviços." Esse mesmo texto enfatiza que a missão é a razão de ser e representa o compromisso da Ambev como empresa. Todavia, a Ambev não se identifica mais apenas por ter uma missão, cultura, valores, mas também por ter um sonho - "O sonho da Ambev é tornar-se a melhor empresa de bebidas do mundo em um mundo melhor. Para isso, a
Companhia baseia suas estratégias de negócio na geração de três pilares: valores econômicos para todos os acionistas e para a sociedade, valores sociais e valores ambientais." Com base em um discurso conciliador que inclui outros grupos sociais, além de acionistas e consumidores, surge a empresa que sonha com um mundo melhor.

A Ambev declara, em seu site corporativo, que a excelência do seu modelo de gestão permite oferecer resultados sustentáveis para os acionistas - empresa reconhecida por sua excelência em gestão. A companhia também declara que está interessada nos problemas sociais e ambientais. $\mathrm{O}$ discurso é ampliado para incluir explicitamente aspectos relacionados aos funcionários e consumidores que não estavam presentes no texto sobre a missão da Ambev em 2006 - além de cidadã, surge a empresa social e ambientalmente responsável, a empresa porta-voz do consumo responsável, a empresa que cuida da sua gente e a empresa que produz e comercializa um produto cujo consumo moderado faz bem para a saúde.

Para expressar essa última identidade, a empresa apoia-se em um banco de dados nacionais e internacionais, que ela define como científicos e confiáveis, do Centro de Informações sobre Saúde e Álcool (CISA), uma ONG que iniciou suas atividades em 2004 com o apoio financeiro da Ambev. A empresa não menciona, porém, em seu site, que um dos seus fundadores não é um consumidor dos produtos que a companhia produz e comercializa: ele não bebe cerveja porque é um atleta (OS PRINCÍPIOS..., 2008).

No decorrer desse drama social, a Ambev desenvolveu diversas performances que lhe permitiram identificar-se não como protagonista dos problemas causados pelo consumo de álcool, mas como protagonista das ações que visam à solução desses problemas. Especialmente na última fase do drama social, a empresa utilizou, com grande frequência, a presença de jogadores de futebol em suas campanhas publicitárias. Como patrocinadora da Copa do Mundo de Futebol em 2010, pôde se identificar como um dos milhões de brasileiros que gostam de futebol - empresa verde-amarela. Vários jogadores da seleção brasileira de futebol tornaram-se interlocutores da companhia e falaram diretamente com milhões de fãs desse esporte, a associação entre cerveja e futebol é explícita.

Isso não significa que a empresa tenha sempre obtido o resultado pretendido com essa associação. Em uma peça publicitária, em 2009, a companhia colocou um importante jogador brasileiro oferecendo um copo de cerveja e sugerindo uma relação entre a sua trajetória de sucesso e o consumo dessa bebida, pois ele se identifica como um brahmeiro! (referência a uma das marcas comercializadas pela Ambev). Por infringir o Código de Autorregulamentação 
Publicitária, incitar o consumo de álcool entre o público jovem e dirigir-se contra o princípio da responsabilidade, essa peça publicitária foi condenada pelo Ministério Público Federal, que exigiu indenização da Ambev.

Já em outra peça publicitária, de 2010, inserida no site corporativo da companhia e em revistas e jornais de circulação nacional, os funcionários são os interlocutores das práticas, políticas e estratégias empresariais. Fotos de funcionários de diferentes posições hierárquicas são acompanhadas por um pequeno texto, no qual o funcionário relaciona a sua trajetória pessoal com a sua participação naquilo que a companhia denomina a Gente Ambev, eles apresentam-se felizes, saudáveis, competentes e bem-sucedidos - surge a empresa de gente que faz a diferença.

\section{IMPLICAÇÕES DO ESTUDO}

Oposição, convergência e integração dos conceitos de IO e IC constituíram o ponto de partida desse estudo. Em busca de outros olhares, conduzimos um diálogo entre os conceitos de identidade da organização e os conceitos de performance e drama oriundos da Antropologia da Performance. Ilustramos esse diálogo com a análise do processo de construção da identidade da companhia Ambev, no decorrer de um drama social relacionado, sobretudo, mas não apenas, aos problemas com o consumo de bebida alcoólica. Um período de contestação de interesses, reciprocidades, expectativas, valores, políticas e estratégias.

No decorrer desse drama social, evidenciamos que a Ambev protagonizou diversas ações simbólicas em variados meios de comunicação para articular, expressar e celebrar diversas identidades, em busca de legitimação social e de protagonismo no ambiente competitivo. Tais performances dramáticas visavam comunicar, convencer, educar, seduzir e transformar diferentes plateias. Nesse processo de construção de identidades que a identificavam com os interesses e as necessidades de cada audiência, a organização também produziu a si mesma.

Desse modo, desde a erupção e no decorrer das etapas posteriores desse drama social, foi possível mostrar que, ao buscar uma nova forma de se apresentar e participar do processo social e da cena competitiva de negócios, os executivos da companhia protagonizaram um processo que combinou negação, revelação, enfrentamento e (re) apresentação. A Ambev foi convertendo-se a si mesma em um mosaico de selves sociais - distintos reconhecimentos e imagens da empresa produzidos pelas distintas plateias no decorrer de um processo de comunicação significativa por meio de performances dramáticas. A empresa- -performer é também empresa-mosaico - "O que ou quem estamos nos tornando como organização?".

Essa metáfora e a questão-orientadora que propomos nesse estudo revelam aspectos não considerados pelas metáforas e questões já difundidas e aqui apresentadas nos estudos funcionalistas, estruturalistas e pós-modernos da identidade de uma organização. Ambas problematizam a identidade da organização como o resultado de experiências individuais e coletivas que vão (trans)formando a organização. Também trazem implicações para as práticas de gestão, pois mostram que as performances constituem o aspecto central da construção da identidade organizacional, especialmente em situações de drama social. As performances organizacionais dramáticas pressupõem criação e escolha de recursos materiais e simbólicos, de natureza multinível (indivíduos, grupos e sociedade) e multidisciplinar (econômica, político-legal, cultural, ética e estética).

As performances organizacionais são fonte de identidade, mas também de legitimação ou deslegitimação, especialmente em situações de crise e de mudança organizacional. O conceito de performance traz as noções de intenção e incerteza para o centro do processo de gestão, pois as performances falham se não satisfazem os seus públicos e seus críticos, a despeito do planejamento que lhes deu origem. Assim, as performances organizacionais dramáticas, como parte do processo de gestão e de estratégia, não apenas constituem a identidade da organização, mas podem influenciar o seu desempenho futuro.

Os conceitos da Antropologia da Performance, quando aplicados às organizações, reafirmam a importância das habilidades dos gestores para lidar com os conflitos e as tensões que emergem nas interações da organização com audiências distintas, pois, ao buscar atender interesses tão distintos, é possível que as performances que a organização protagoniza sejam vistas como coerentes, se olhadas isoladamente, mas ambíguas e contraditórias, se olhadas ao longo do tempo.

Conceitualmente, as noções de performance e de drama exigem um outro entendimento para aquelas características da identidade organizacional identificadas por Albert e Whetten (1985). A Antropologia da Performance, em sua perspectiva pós-moderna, leva-nos a recusar a noção de identidade organizacional como algo central e durável; ao mesmo tempo, renova a ideia de que identidade é algo que distingue uma organização das demais. Não há como falar de centralidade em organizações mutantes, que não apenas apresentam múltiplas identidades, mas que se dispõem a transformar cada uma delas à medida que se tornam inadequadas, não adaptadas ou ilegítimas. Afinal, 
são as plateias e os críticos que irão avaliar e julgar as performances apresentadas pela organização e o grau em que essa performance responde ou atende os seus interesses, expectativas e sonhos.

Do mesmo modo, também não é razoável considerar a noção de continuidade em identidades organizacionais, se as performances organizacionais articulam, expressam e celebram somente as identidades que: (1) proporcionam suporte político interno e externo para as estratégias e a existência da organização e (2) apoiam ou sustentam elevados resultados econômicos. As características identitárias que se mostram desfavoráveis ou neutras para o desempenho organizacional e a existência lucrativa da companhia tendem a ser ocultadas ou negadas em suas performances. Performances organizacionais dramáticas, protagonizadas pela organização, não são avaliadas apenas por plateias e críticos, mas também pela própria organização. Os gestores avaliam e julgam as múltiplas identidades da organização reveladas em performances cotidianas, não apenas pelas potencialidades estética, moral e de construção de sentido, mas também pelo retorno econômico.

Os conceitos de performance e drama renovam a noção de distinção como parte do conceito de identidade organizacional, pois mostram que uma organização se distingue pela capacidade de seus gestores de mobilizar os elementos centrais do imaginário social para (re)inventar a organização, por meio de performances, especialmente em situações de drama social, que satisfaçam as plateias e os críticos da organização, e contribuam favoravelmente com uma existência lucrativa da companhia.

\section{CONCLUSÃO}

Inicialmente não buscamos uma filiação teórica para o nosso estudo, porém a perspectiva pós-moderna é aquela que abriga o conceito que propomos de identidade organizacional como drama e atos de performance. Esse conceito não somente revela a empresa como um mosaico de selves sociais, mas nos permite entender que o processo de tornar-se uma organização é inescapavelmente performativo, em um mundo cada vez midiatizado. A empresa-performer é aquela que interpreta, utiliza, revisa e expressa significados em suas performances para se (re)inventar .

Apresentamos um estudo de natureza exploratória, dado o estado incipiente da difusão e/ou aplicação dos conceitos da Antropologia da Performance nas pesquisas sobre identidade da organização. Desse modo, outros estudos que ampliem e aprofundem as possibilidades de aplicação desses conceitos à questão da identidade da or- ganização fazem-se necessários. Destacamos três direções para esses futuros estudos: a relação entre estética e moral na linguagem contemporânea de performances organizacionais dramáticas; as perspectivas epistemológicas que favorecem o entendimento de performances organizacionais cotidianas e, em muitas situações, dramáticas; e o estudo das questões ontológicas suscitadas pela metáfora da empresa-mosaico.

\section{REFERÊNCIAS}

ALBERT, S. The definition and metadefinition of identity. In: WHETTEN, D. A; GODFREY, P. C. (Ed). Identity in organizations. Thousands Oaks; London; New Delhi: Sage Publications Inc., 1998. p. 1-16.

ALBERT, S; WHETTEN, D. A. Organizational identity. In: CUMMINGS, L. L; STAW, B. M. (Eds). Research Organizational Behavior, Greenwich, CT: JAI Press, 1985. v. 7, p. 263- 295

AMBEV. Site corporativo. Disponível em: http://www.ambev.com.br Acesso em: 17.07.2010.

BOUCHIKI, $\mathrm{H}$ e outros. The identity of organizations. In: WHETTEN, D. A; GODFREY, P. C. (Eds). Identity in organizations. Thousands Oaks; London; New Delhi: Sage Publications Inc., 1998. p. 33-82.

BROWN, A. D. A narrative approach to collective identities. Journal of Management Studies, v. 43, n. 4, p. 731-753, 2006.

BROWN, T. J; DACIN, P. A; PRATT, M. G; WHETTEN, D. A. Identity, intended image, construed image, and reputation: an interdisciplinary framework and suggested terminology. Journal of The Academy of Marketing Science, v. 34, n. 2, p. 99-106, 2006

BRUNER, E. M. Experience and its expressions. In: TURNER, V. W; BRUNER, E. M. (Eds). The Anthropology of performance. Chicago: University of Illinois Press, 1986. p. 3-30.

CALDAS, M. P; WOOD JR, T. Identidade organizacional. RAE-revista de administração de empresas, v. 37, n. 1, p. 6-17, 1997.

CARRIERI, A. de P; PAES-DE-PAULA, A. P; DAVEL, E. Identidade nas organizações: múltipla? Fluída? Autônoma? Revista Organização E Sociedade, v. 15, n. 45, p. 127-144, 2008

CHRISTENSEN, L. T; CHENEY, G. Absorption and seduction in the corporate identity game. In: SCHULTZ, M; HATCH, M. J; LARSEN, M. H. The expressive organization. Oxford; New York: Oxford University Press, 2000. p. 246-270.

CORLEY, K. G. e outros. Guilding organizational identity through aged adolescence. Journal of Management Inquiry, v. 15, n. 2, p. 85-99, 2006.

CZARNIAWSKA, B. Identity lost or identity found? Celebration and lamentation over the postmodern view of identity in Social Science fiction. 
In: SCHULTZ, M; HATCH, M. J; LARSEN, M. H. The expressive organization. Oxford; New York: Oxford University Press, 2000. p. 271-283.

DAWSEY, J. C. O teatro dos "bóias-frias": repensando a Antropologia da performance. Horizontes Antropológicos, Porto Alegre, v. 11, n. 24, p. 1534, 2005.

DUTTON, J. E; DUKERICH, J. M. Keeping an eye on the mirror: image and identity in organizational adaptation. Academy of Management Journal, v. 34, n. 3, p. $517-554,1991$.

FONTENELLE, I. A. Construção e desconstrução de fronteiras e identidades organizacionais: história e desafios do McDonald's. RAE-revista de administração de empresas, v. 47, n. 1, p. 60-70, 2007.

GIOIA, D. A; SCHULTZ, M.; CORLEY, K. G. Organizational identity, image and adaptative instability. Academy of Management Review, v. 25, n. 1, p. 663-681, 2000.

GLYNN, M. A. When cymbals become symbols: Conflict over organizational identity within a symphony orchestra. Organization Science, v. 11, n. 3, p. $285-298,2000$.

GOFFMAN, E. The presentation of in everyday life. London: Penguin Books, 1990.

HARDY, C; PALMER, I; PHILLIPS, N. Discourse as a strategic resource. Human Relations, v. 53, n. 9, p. 1227-1248, 2000.

HASLAM, S. A; POSTMES, T; ELLEMERS, N. More than a metaphor: organizational identity makes organizational life possible. British Academy of Management, v. 14, n. 1, p. 357-369, 2003.

HATCH, M. J; SCHULTZ, M. Relations between organizational culture, identity and image. European Journal of Marketing, v. 31, n. 5/6, p. 356365, 1997.

HATCH, M. J; SCHULTZ, M. Scaling the Tower of Babel: relational differences between identity, image, and culture in organizations. In: SCHULTZ, M; HATCH, M. J; LARSEN, M. H. The expressive organization. Oxford; New York: Oxford University Press, 2000. p. 11-35.

HATCH, M. J; SCHULTZ, M. The dynamics of organizational identity. In: HATCH, M. J; SCHULTZ, M. (Eds) Organizational identity. Oxford; New York: Oxford University Press, 2004. p. 377-403.

MÉDICO quer lobby contra a indústria. [Reportagem local]. Folha de S. Paulo, São Paulo, 27.10.2003. Caderno Cotidiano. Disponível em: http://wwwl.folha.uol.com.br/fsp/cotidian/ff2710200312.htm. Acesso em 27.10.2007.

MACHADO, H. V. Identidade organizacional: um estudo de caso no contexto da cultura brasileira. RAE-eletrônica, v. 4, n. 1, 2005. Disponível em: http://wwwl6.fgv.br/rae/redirect.cfm?ID=2029. Acesso em 23.03.2008.

MACHADO-DA-SILVA, C. L; NOGUEIRA, E. E. da S. Identidade organizacional: um caso de manutenção, outro de mudança. Revista de Administração Contemporânea, Ed. Especial, v. 5, 2001.
NEVES, M. L; CANÇADO, P. Cultura envelhecida. Revista Época Negócios, ed. 411, abr/2006. Disponível: http://revistaepoca.globo.com/Epoca/0,69 93,EPT1168579-1662-2,00.html. Acesso em 25.09.2007.

NUNES, J. H. Interacionismo simbólico e dramaturgia. São Paulo: Humanitas; Goiânia: UFG, 2005.

OS PRINCÍPIOS de uma vitoriosa cultura de gestão do Brasil, HSM Management, ano 12, v. 6, n. 66, p. 14-24, 2008.

PRATT, M. G; FOREMAN, P. O. Classifying managerial responses to multiple organizational identities. Academy of Management Review, v. 25 , n. 1, p. 18-42, 2000.

RAVASI, D; SCHULTZ, M. Responding to organizational identity threats: Exploring the role of organizational culture. Academy of Management Journal, v. 49, n. 3, p. 433-458, 2006.

RINDOVA, V. P; POLLOCK, T. G; HAYARD, M. L. A. Celebrity firms: the social construction of market popularity. Academy of Management Review, v. 31, n. 1, p. 50-71, 2006

SCHECHNER, R. Performance Studies. New York: Routledge, 2006.

SCHECHNER, R. Performance Theory. New York: Routledge, 2003.

SCHULTZ, M; HATCH, M. J; LARSEN, M. H. Introduction: why the expressive organization? In: SCHULTZ, M; HATCH, M. J; LARSEN, M. H. The expressive organization. Oxford; New York: Oxford University Press, 2000. p. 1-10.

SCOTT, S. G; LANE, V. R. A stakeholder approach to organizational identity. Academy of Management Review, v. 25, n. 1, p. 43-62, 2000.

STIMPERT, J. L. L; GUSTAFSON, L. T; SARASON, Y. Organizational identity within the strategic management conversation. In: WHETTEN, D. A; GODFREY, P. C. (Eds). Identity in organizations. Thousands Oaks; London; New Delhi: Sage Publications Inc., 1998. p. 33-82.

TURNER, V. On the edge of the Bush. Tucson, Arizona: The University Of Arizona Press, 1985.

TURNER, V. Introdução. Drama, fields, and Metaphors. Itchaka, New York: Cornell University Press, 1975. p. 13-19

VAI UMA cervejinha aí? Folha de S. Paulo, São Paulo, 29.10.2007. Caderno Folhateen. p. 4-7

WHETTEN, D. A. Albert and Whetten revisited: strengthening the concept of organizational identity. Journal of Management Inquiry, v. 15, n. 3, p. 219-234, 2006.

WHETTEN, D. A; GODFREY, P. C. (Eds). Identity in organizations. Thousands Oaks; London; New Delhi: Sage Publications Inc., 1998.

WOOD JR, T. Organizações de simbolismo intensivo. RAE-revista de administração de empresas, v. 40, n. 1, p. 20-28, 2000.

YBEMA, S. Talk of change: Temporal contrasts and collective identities. Organization Studies, v. 31, n. 4, p. 481-503, 2010. 